(Supporting Information for the ACS Applied Bio Materials)

\title{
Development of Injectable Tissue-Adhesive Hybrid Hydrogel for Growth Factor-Free Tissue Integration in Advanced Wound Regeneration
}

\author{
Md. Hasan Turabee, ${ }^{\dagger}$ Thavasyappan Thambi, ${ }^{\dagger}$ and Doo Sung Lee* \\ School of Chemical Engineering, Theranostic Macromolecules Research Center, \\ Sungkyunkwan University, Suwon 16419, Republic of Korea
}

†These authors contributed equally to this work.

*Corresponding author:

Doo Sung Lee, Ph.D.

Tel.: +82-31-299-6851; Fax: +82-31-299-6857; e-mail: dslee@skku.edu 
Table S1. Physicochemical characteristics of PCLA copolymers.

\begin{tabular}{llllllll}
\hline PCLA-PEG-PCLA & PEG & CL and LA & CL and LA & $\boldsymbol{M}_{\mathbf{n}}{ }^{\mathbf{a}}$ & $\boldsymbol{M}_{\mathbf{n}} \mathbf{b}^{\mathbf{b}}$ & $\boldsymbol{\Xi}^{\mathbf{b}}$ \\
& & $\boldsymbol{M}_{\mathbf{n}}$ & feed ratio & feed ratio & & & \\
\hline PCLA-01 & $1500-1620-1500$ & 1620 & 2.5 & 2.95 & 4530 & 4281 & 1.39 \\
PCLA-02 & $1200-1620-1200$ & 1620 & 2.5 & 2.68 & 3820 & 3895 & 1.57 \\
PCLA-03 & $1500-1500-1500$ & 1500 & 2.5 & 3.03 & 4368 & 3919 & 1.36 \\
\hline
\end{tabular}

${ }^{\mathrm{a} C a l c u l a t e d ~ f r o m ~}{ }^{1} \mathrm{H}$ NMR.

${ }^{b}$ Calculated using GPC.

Table S2. Physicochemical characteristics of Gel-PCLA conjugates.

\begin{tabular}{lll|ll}
\hline Conjugates & Feed molar ratio & \multicolumn{2}{c}{ Conjugation ratio } & Hydrogel property \\
\cline { 4 - 5 } & (Gelatin: PCLA) & ${ }^{1} \mathrm{H} \mathrm{NMR}^{\mathrm{a}}$ & TNBS $^{\mathrm{b}}$ & \\
\hline Gel-PCLA1 & $1: 30$ & $1: 9.61$ & $1: 8.96$ & Cannot form gel in vitro gel \\
Gel-PCLA2 & $1: 40$ & $1: 15.17$ & $1: 13.98$ & Cannot form gel in vitro gel \\
Gel-PCLA3 & $1: 50$ & $1: 22.11$ & $1: 19.38$ & Can form in vitro gel \\
\hline
\end{tabular}

${ }^{a}$ Calculated using ${ }^{1} \mathrm{H}$ NMR.

${ }^{\mathrm{b}}$ Calculated from TNBS assay. 
A
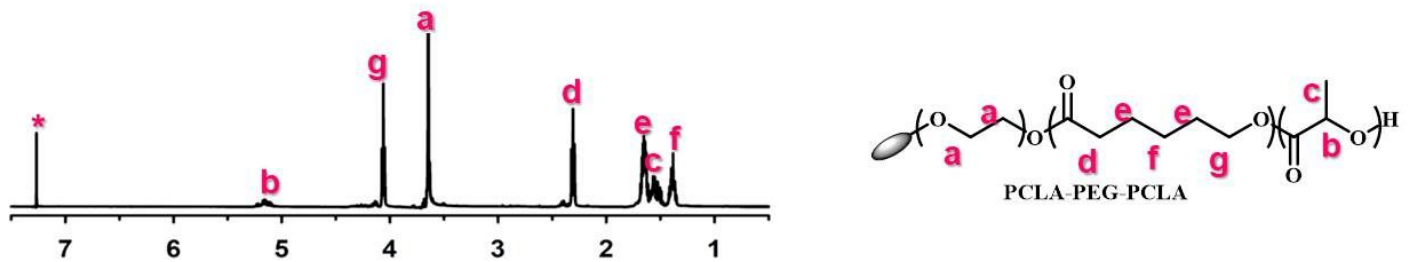

B
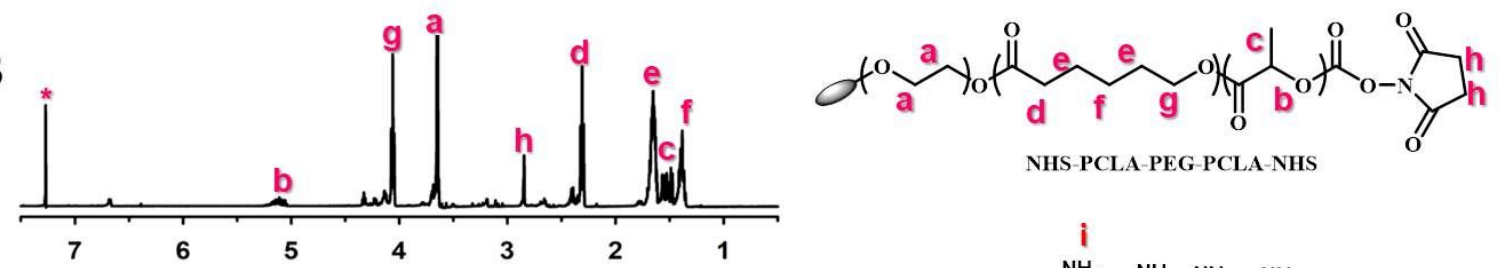

C

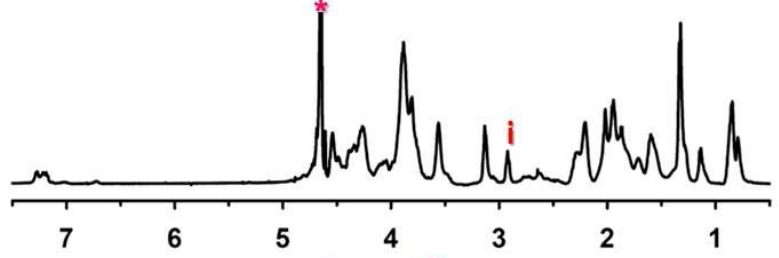

D

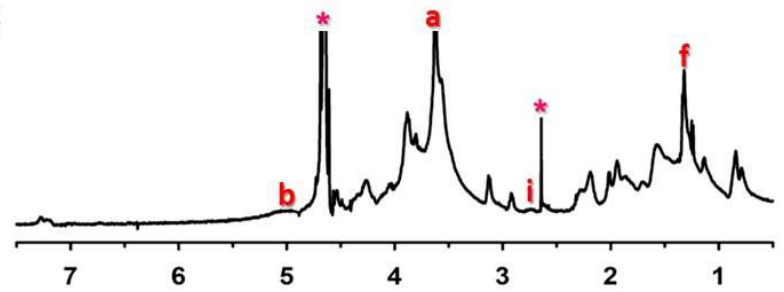

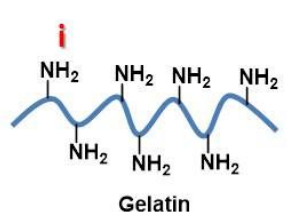
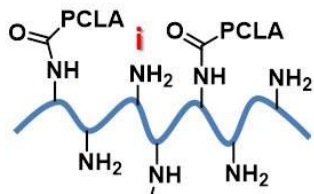
0 Gel-PCLA conjugate

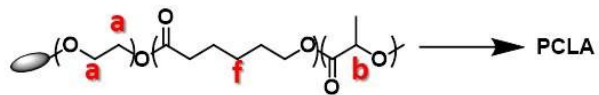

Figure S1. ${ }^{1} \mathrm{H}$ NMR spectra of (A) PCLA, (B) PCLA-NHS, (C) Gelatin, and (D) Gel-PCLA conjugate. 


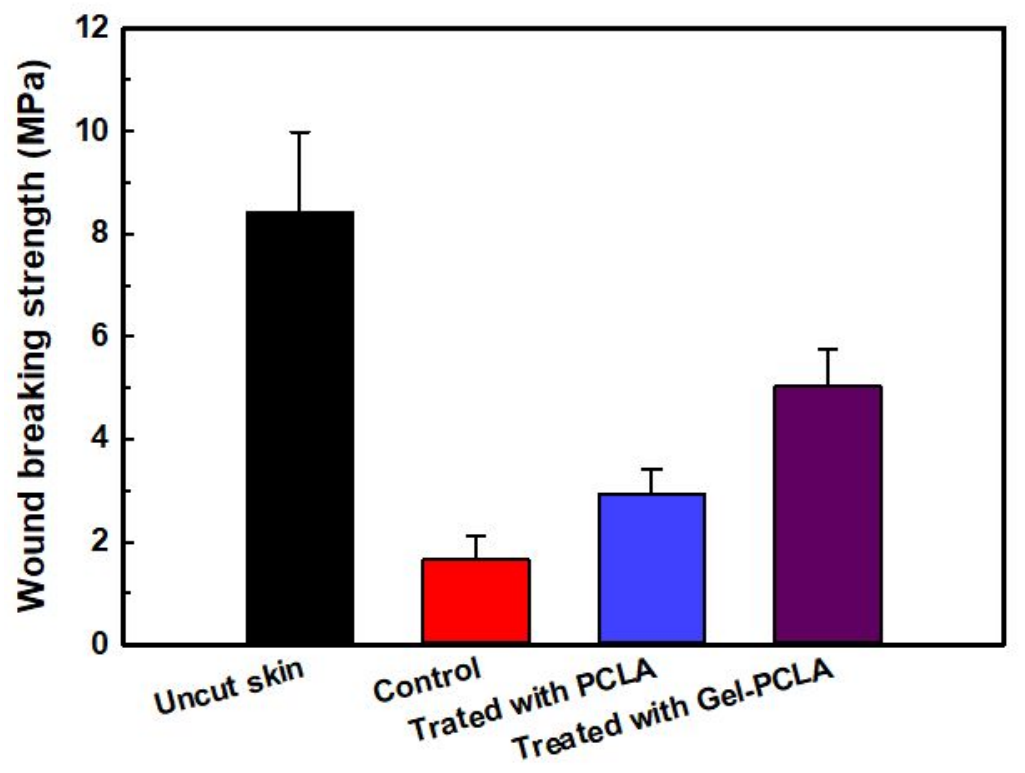

Figure S2. Wound breaking strength of different samples. 